human beings addicted to cannibalism, who had gnawed the bones so as to get at the marrow in the medullary cavities. Dr. Reisner suspected the inaccuracy of both explanations for several reasons, one of which was that he had already noticed the partiality of these lesions for the under surfaces of the bones as they happened to lie in the ground.

Forewarned by the knowledge of these facts from the commencement of my field work I have kept particular note of the circumstances under which these so-called syphilitic lesions occur. During the last six years I have seen a very large number of such "ulcers," both in the skull and in the other bones of the skeleton. The first example that came under my notice at Naga-ed-dêr is shown in Figs. 2 and 3. This case was submitted to a thorough examination and the causal agent was demonstrated beyond any possibility of doubt; in the light of the knowledge thus gained I have had no difficulty in recognising damage produced in the same way in many scores of cases in the course of my field work and can certainly identify the lesions so admirably represented in Professor Lortet's photographs (op. cit. supra, Fig. 37, p. 42, and Pl. I.) as perfectly characteristic examples of the same thing. In the vast majority of cases these injuries occur on that side of the bone that happens to be undermost and especially on those parts which are pressed tightly against the soil. Thus, in the case of prehistoric people buried lying on the left side the "ulcers" are most commonly found on or near the left parietal eminence and the left malar bone (compare Lortet's case). At other periods the body was often placed in the soil lying on the right side or flat on the back; in such cases the lesions occur on the right side of the skull or on the occipital bone respectively. If the bones have been disturbed by ancient plunderers and the skull comes to lie face downwards it is the frontal bone and face that will be attacked (compare Fouquet's typical case). Sometimes the upper surface of a bone or skull may be attacked, but in such cases the damage as a rule is much slighter and is merely an outlying part of the much more severe injury to the under surface (compare Lortet's case).

The following list of undoubted facts can bear only one interoretation-namely, that the injuries were inflicted after death. These "nlcers" are found only in the case of bones that are in contact with the soil. Bodies buried in rock-cut tombs or in coffins are exempt from such injuries. Moreover, a white powder, consisting of pulverised bone, is often sprinkled over the damaged part and the adjoining soil ; in many cases this is so obviously fresh that its age cannot be more than a few months, whereas the bones had been in the soil for thousands of years.

When such a mutilated bone is removed from the soil the burrows of small animals (Fig. 4) can always be seen leading to the "ulcer." Fragments of the soil from the walls of these burrows and also that taken from the damaged surfaces of bones were examined by my colleague, Professor Looss, and found to contain fragments of the elytra of beetles. The burrows, usually about one millimetre in diameter, must have been formed by very small beetles, which also caused the damage to the bones. That this is no mere inference but a demonstrable fact is shown at once if the edges of the "ulcers" be examined by means of a lens. 'The little grooves produced by the scraping of the beetles are distinctly visible. Professor Looss suggested the search for this characteristic feature. As a rule the soil around the "ulcer" is converted into a hard cake, which firmly adheres to the bone (Fig. 2). This is no doubt caused by the excretion of sticky fluids from the beetles' bodies. Such masses usually form a cap over each hole produced by beetles in bone, and if such a cap be removed (Figs. 3 and 4 ) it will be found to be riddled with the burrows of the insects, which have caused the damage to the bone (Fig. 4). The white spots and the areas devoid of polish, which Professor Lortet has described (vide supra), are merely the results of the earlier stages of the beetles' attack on the bone (see Figs. 2 and 3).

I do not think there can be any doubt whatsoever that the injuries described by Professor Lortet and Dr. Fouquet as the results of syphilis were really produced long after death and burial and that the damage was done by small beetles.

I do not pretend to be competent to discuss the larger question whether any of the ante-mortem lesions found in the ancient Egyptian bones in our collection are the results of syphilis. But no case has yet been found which competent pathologists are willing to attribute to the action of the syphilitic virus to the exclusion of all other possible causal factors. Moreover, among the very large number of ancient Egyptian skeletons that have come under my notice during the last seven years I have seen only two cases in which even the possibility of a syphilitic origin presented itself. Not a single tooth from an ancient Egyptian cemetery has been seen to exhibit any trace of the effects of syphilis or anything even resembling it. We are therefore bound to admit that, so far as we know at present, syphilis did not occur in Egrpt before the time when intimate communication with Europe was established.

Cairo.

\section{A DIGEST OF EIGHTY-SIX CASES OF EPI DEMIC CEREBRO-SPINAL MENINGITIS ADMITTED TO THE MIDDLE WARD HOSPITAL, MOTHERWELL, IN 1907.}

BY ERNEST WATT, M.D. GLASG., D.P.H.,

ASSISTANT MEDICAL OFFICER OF HEALTH, COUNTY OF LAYARK.

THE following notes give a short account of the symptomatology, diagnosis, and treatment of 86 cases of cerebrospinal meningitis which I had under supervision in the Middle Ward Hospital, Motherwell, during 1907, accompanied by a brief note on the bacteriology of the cases.

Symptomatology. - The following table shows the more prominent symptoms and the frequency with which each was observed :-

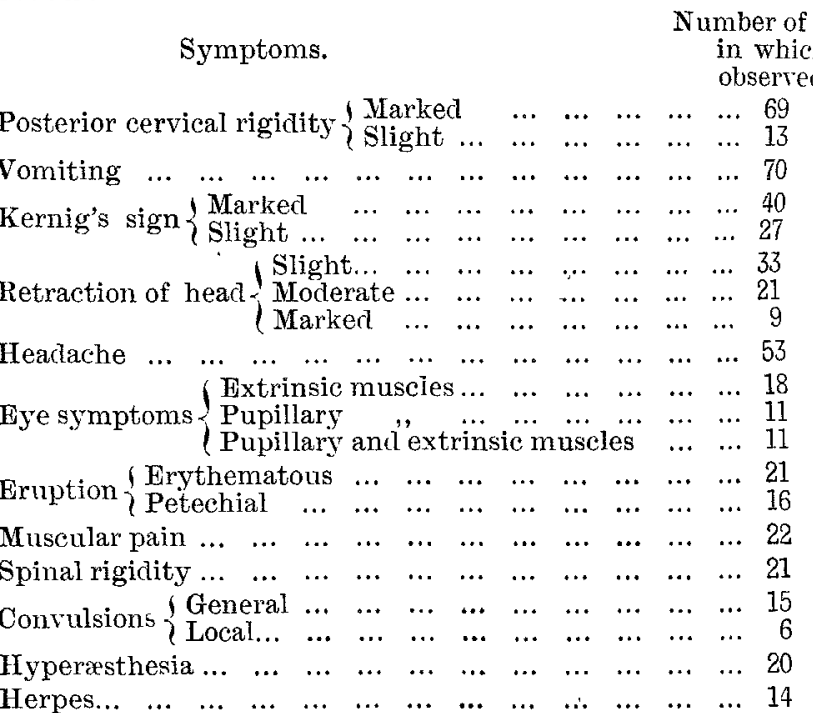

The condition most frequently present was rigidity of the posterior cervical muscles. It was met with in $82(95 \cdot 3$ per cent.) of the cases. It occurred in the earliest cases brought uncler observation and was present in a marked degree in 69 cases. In 13 cases this condition was found in only a slight degree and in four it was absent. Two of these last were in a deeply comatose condition on admission and two were convalescent. To elucidate this sign the patient should be placed in the position of dorsal decubitus; with the hand under the occiput an attempt is made to flex the head. Should rigidity be present the movement is resisted and if the attempt to flex the head be persevered in the patient's shoulders are raised off the bed and little or no flexion movement occurs. Similarly, where it is inexpedient to place the patient on his back the trunk moves across the bed when flexion of the head is attempted. This rigidity is volitional and disappears under the influence of a general anæsthetic ; in several cases also it was not present after the patient had become comatose, but in two cases in which the coma had passed off the rigidity again set in. Only when the patients were advanced in convalescence did we find the movements of flexion and extension of the head free.

Vomiting at the onset of illness was present in 70 casesa percentage of $81 \cdot 39$. As one must largely trust to the statements of the patient's friends the frequency with which vomiting occurs as an initial symptom must be accepted with caution, and probably the percentage here given is too low.

In 53 cases there was a definite history of headache. It 
was a constant feature in the aciult cases, and as so many patients were too young to give expression to their feelings an accurate estinate of the occurrence of hearlache must ever remain impossible. The headache is usually very severe and causes the patient to cry out at intervals, and in children a good deal of the restlessneas met with is probably due to this cause.

Muscular pains, especially in the back and legs, were noted in 22 cases. This was seldom a constant feature, but in those passing into the hydrocephalic stage severe pains were complained of on moving the patient in bed. Hyperxsthesia was a pronounced feature in 20 cases. It most commonly occurred towards the end of the febrile period and lasted into the hydrocephalic stage. In many cases it was so pronounced that even striking the bed with the hand caused the patient to crv out.

Kernig's sign was present in a marked degree in 40 cases and in a slight degree in 27. It was present in all of the adult cases.

Symptoms referable to the eye were met with in 40 cases. In 18 of these the extrinsic muscles of the eyeball alone were involved. The external rectus was the one most commonly involved and therefore internal strabismus was most frequently observed. 11 cases exhibited pupillary symptoms. Generally these consisted in inequality of the pupils during the early stages of the illness, but when the patient had passed into the hyclrocephalic stage the condition was usually one of dilated pupils with sluggish reaction to light. In the remaining 11 cases both pupillary signs as well as those referable to the orbital muscles were seen. In all of the cases which passed into the hydrocephalic stage a certain degree of photophobia was met with, the patient showing a marked preference to lie with the face covered by the bedclothes.

Fifteen cases developed general "convulsions." Mostly this condition occurred in the fulminant type of case, though in a few of the less rapidly fatal type it was met with. The "convalsions" were tonic in character at the commencement, becoming clonic as the attack passed off. Six other cases showed convulsive movements, principally tonic in character, of one or more limbs, and in all of these the neck and face muscles were also involved. Noisy delirium occurred in 21 cases and in a few of these (fulminant) it assumed a violent character.

Retraction of the head was met with in 63 cases, a percentage of $73 \cdot 2$. In 33 cases the condition was only slight, in 21 it was fairly well marked, and in nine the head was thrown so far back that it almost touched the scapulæ and deglutition was impossible. As a rule, marked retraction occurs only in the acute stage of the illness and becomes less pronounced is this passes off. Where, however, the stage of hydrocephalus has developed a certain degree of retraction remains. In the accompanving reproductions of photographs of one case the progressive tendency of the condition is well seen.

In 14 cases a herpetic eruption, principally about the lips, nose, and neck, was met with. In one instance the condition

Frg. 1.

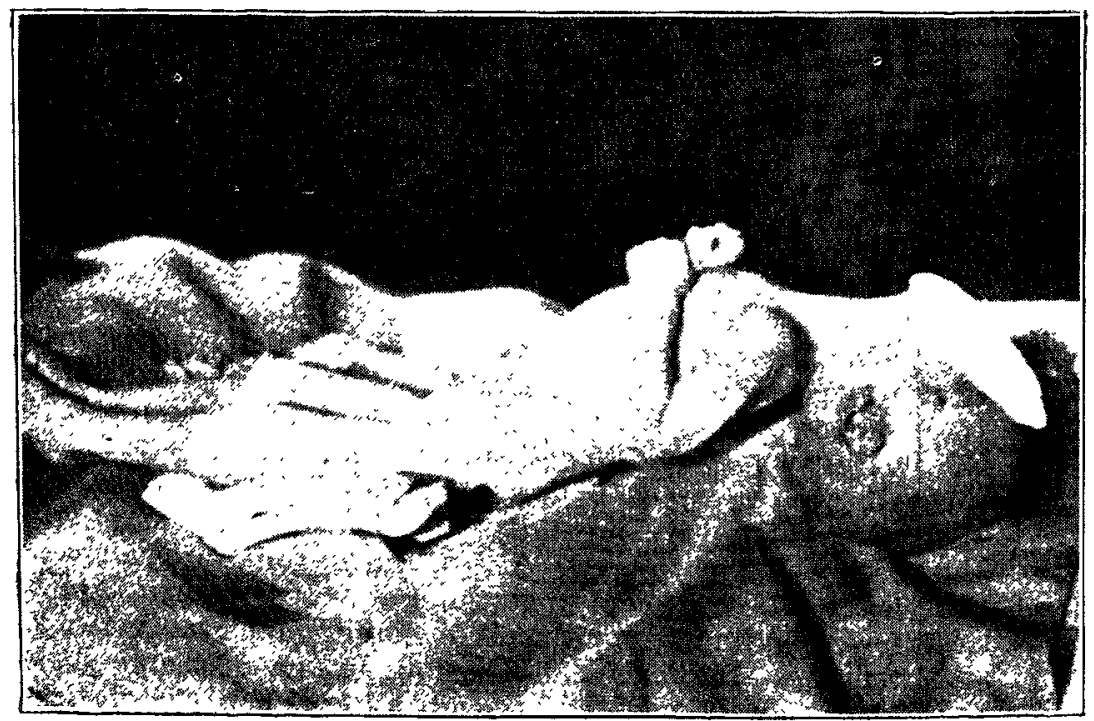

Shows the patient in the third week of illness.
FIG. 2.

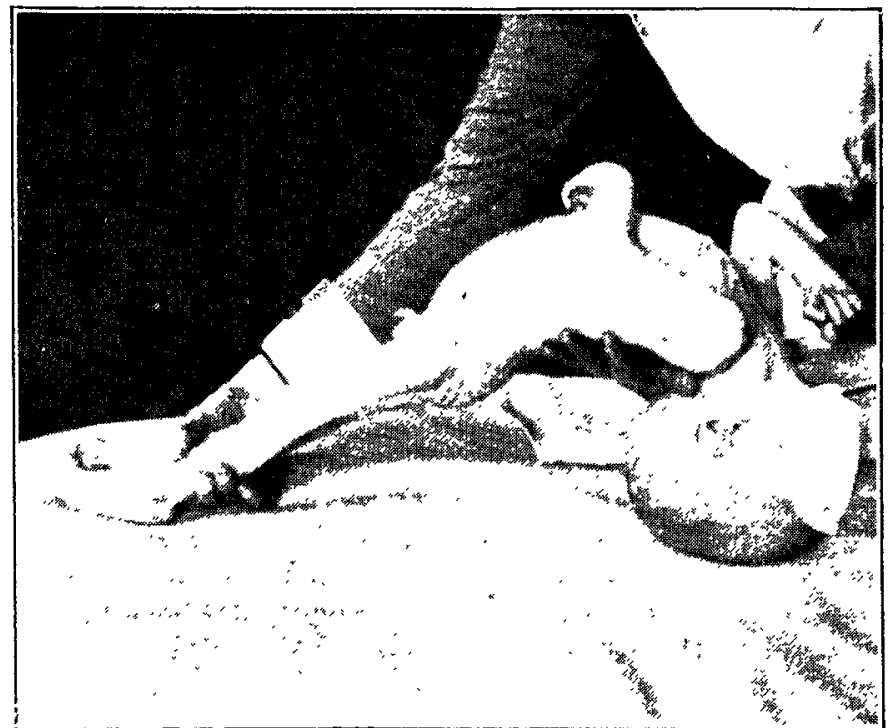

Shows the patient in the fifth week of illness.

FIG. 3.

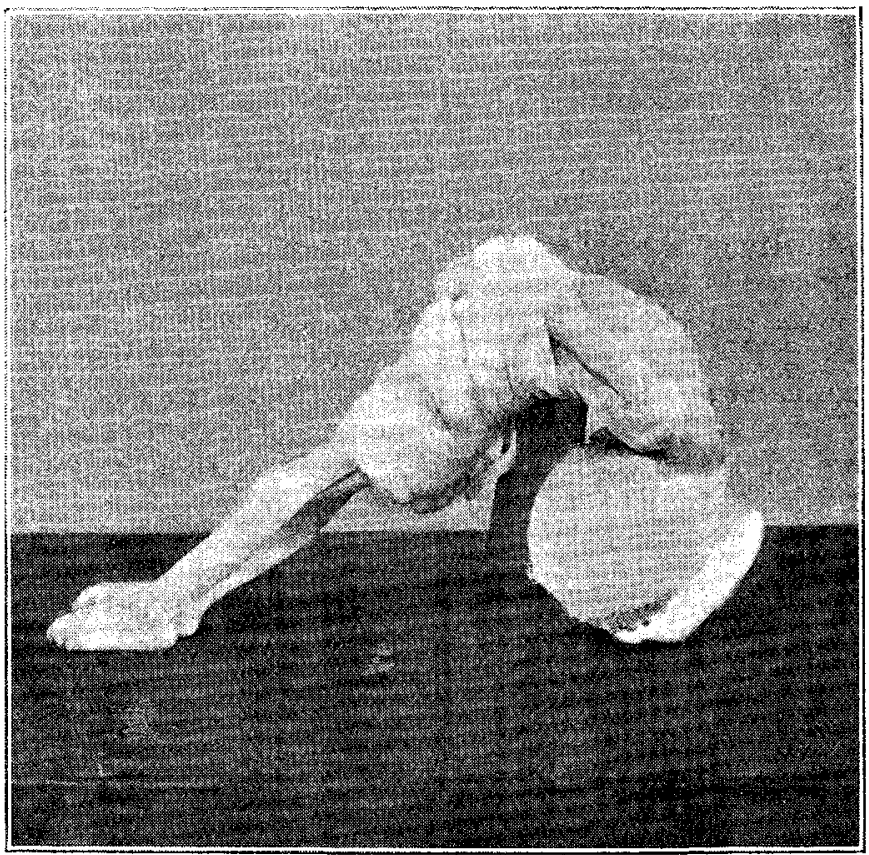

Taken after patient's cleath in the ninth week of illness. The emaciation is very striking.

was very extensive and involved not only the lips and chin but also the upper part of the right anterior triangle of the neck. This eruption was found to occur in the early stage of the illness and was limited, with few exceptions, to the severe form of the disease.

A petechial eruption of the skin was seen in 16 cases and an erythematous in 21 cases. In three of the fulminant cases the former conclition existed on the trunk and extremities as dusky irregular areas from a quarter to half an inch in diameter. In the remaining cases showing petechiæ on the skin the eruption consisted of scanty small areas of hæmorrhage varying in size from a sixteenth of an inch to an eighth of an inch across, principally limited to the chest, back, and abdomen, and less often seen on the flexor surfaces of the arms and front of the thighs. Of the 21 cases which showed an erythematous eruption, one (fatal case) was morbilliform in type, but it did not involve the face. In all of the others the condition was an erythema of the trunk 
and sometimes of the extremities and varied from a faint blush of the skin to a more dusky condition.

Diagnosis.-A history of vomiting (sudden) and severe headache occurring in an apparently healthy child should, during an epidemic of cerebro-spinal meningitis, raise suspicions of the disease. A not uncommon history obtained is that the child was at play and suddenly complained of sickness and headache and within a few hours its condition is desperate and unconsciousness supervenes. In such cases there is seldom much retraction of the head but rigidity of the neck I have found to be invariably present even in the cases where death ensued within 24 hours from the onset of symptoms. Retraction of the head is a distinctly suggestive condition when it occurs but it is met with in other head conditions, such as tuberculous meningitis, and is also seen in inflammatory conditions in the tissues of the neck. A symptom which is invariably present except when the patient is comatose is rigidity of the cervical muscles (as described under "symptomatology") When this condition exists in any marked degree a provisional diagnosis of cerebro-spinal meningitis may be given.

To confirm the diagnosis in doubtful cases lumbar puncture to obtain the cerebro-spinal fluid should be done. This operation is a simple one in infants and young children as no anæsthetic is required. In children of four years of age and upwards, and especially in adults, a general anæsthetic should be given : in the first plase to prevent alarming the patient by causing pain, and in the second in order to have the spine immobile during the operation. In the case of children under the age of five years the needle need not be longer than two inches, but for older children and adults it must be three inches at least in length. In infants under 18 months the needle is best introduced in the mid-line, in older children a quarter of an inch to one side of this, and in the case of the adult half an inch from the mid-line. The fourth lumbar interspace is the most convenient, as it will be found practically on a level with the iliac crests. The needle when introduced in the mid-line should be directed very slightly upwards, and when introduced to one side it should be directed slightly upwards and towards the mid-line of the spinal canal. As few diplococci are found in many of the fluids obtained, not less than 5 cubic centimetres should be drawn off into a sterile receptacle: this is then sealed and sent to a convenient bacteriological laboratory.

In regard to the naked-eye appearance of the fluids drawn off in the cases under observation for bacteriological purposes from the cases in hospital 15 were persistently clear, 23 were turbid, 32 were purulent, in two the fluid was blood-stained, and in 14 its appearance was not noted.

Iable showing the Result of the Bacteriological Examination (a) of the Fluid obtained by Lumbar Puncture and (b) of the Patient's Blood.

\begin{tabular}{|c|c|c|c|c|c|}
\hline \multicolumn{2}{|c|}{$\begin{array}{l}\text { Meningococcus } \\
\text { present. }\end{array}$} & \multicolumn{2}{|c|}{$\begin{array}{c}\text { Fluid.-Direct examina } \\
\text { Meningococcus } \\
\text { not found. }\end{array}$} & \multicolumn{2}{|c|}{ Unknown. } \\
\hline $\begin{array}{l}\text { Fatal } \\
\text { cases. } \\
20\end{array}$ & $\begin{array}{l}\text { Recovered } \\
\text { cases. } \\
6\end{array}$ & $\begin{array}{l}\text { Fatal } \\
\text { cases. } \\
34\end{array}$ & $\begin{array}{l}\text { Recovered } \\
\text { cases. } \\
15\end{array}$ & $\begin{array}{l}\text { Fatal } \\
\text { cases. } \\
3\end{array}$ & $\begin{array}{l}\text { Recovered } \\
\text { cases. } \\
8\end{array}$ \\
\hline \multicolumn{6}{|c|}{86} \\
\hline \multicolumn{2}{|c|}{$\begin{array}{l}\text { Meningococcus } \\
\text { present. }\end{array}$} & \multicolumn{2}{|c|}{$\begin{array}{l}\text { Flaid._On culture. } \\
\text { Meningococcus } \\
\text { not found. }\end{array}$} & \multicolumn{2}{|c|}{ Unknown. } \\
\hline $\begin{array}{l}\text { Fatal } \\
\text { cases. } \\
42\end{array}$ & $\begin{array}{l}\text { Recovered } \\
\text { cases. } \\
18\end{array}$ & $\begin{array}{l}\text { Fatal } \\
\text { cases. } \\
12\end{array}$ & $\begin{array}{l}\text { Recovered } \\
\text { cases. } \\
3\end{array}$ & $\begin{array}{l}\text { Fatal } \\
\text { cases. } \\
\quad 3\end{array}$ & $\begin{array}{l}\text { Recovered } \\
\text { cases. } \\
8\end{array}$ \\
\hline \multicolumn{6}{|c|}{86} \\
\hline \multicolumn{6}{|c|}{$\begin{array}{l}\text { Blood.-On culture. } \\
\text { Meningococcus present. }\end{array}$} \\
\hline & $\begin{array}{l}\text { Fatal } \\
\text { cases. } \\
5\end{array}$ & $\begin{array}{l}\text { Recovered } \\
\text { cases. } \\
5\end{array}$ & & 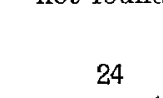 & \\
\hline
\end{tabular}

It is seen on looking at this table that in 20 fatal cases ( $23 \cdot 2$ per cent. of the total) the specific organism was found on direct examination of the fluid and also in 6 of the "recovered" cases (6.9 per cent. of the total). In 49 cases the specific organism was not found and in 11 cases no record was kept.

A much higher percentage of positive results was obtained when cultures of the fluid were examined. Thus in 60 instances (or 69.7 per cent. of the total) the specific organism was found; in 15 (or 17.4 per cent.) the organism was not found, and in 11 no record was kept. The blood taken from 34 cases in the febrile stage of the disease was found to contain the specific organism in 10 instances on culture. The other 24 gave a negative result. Of those which gave a positive result 5 had a fatal issue and 5 recovered.

Treatment. - In the acute fulminant type of cases little can be done except to ameliorate the most pronounced symptoms. Thus, where headache is severe relief of intradural pressure by lumbar puncture frequently converts a very restless patient into a comparatively quiescent one for a few hours. In the less acute type of case exhibiting recurring attacks of headache, rises of temperature, and perhaps vomiting, lumbar puncture is indicated on the recurrence of each attack. By using a needle of fine calibre (except where flakes of pus have been found formerly) and allowing the fluid to slowly trickle ont large quantities may be removed, and not infrequently from 1 to 2 ounces are drawn off in about 20 minutes. The advantages of using a fine needle are that less pain is caused during introduction, the pressure is gradually relieved, and there is less chance of injuring the cauda equina.

Special treatment in the form of various sera was tried in 49 cases. These were selected as acute cases. In 22 the serum was given subcutaneously and in 27 intradurally. The percentage of recoveries was no greater than the total-viz., $32 \cdot 7$ per cent. and $32 \cdot 6$ per cent. respectively. When given early in the disease the serum seems to mitigate somewhat the tendency to hydrocephalus. In making comparisons in this disease an important fallacy crops up-namely, alteration in severity of type of disease. Thus towards the end of 1907 the cases admitted were not so seriously ill as those admitted during the spring and early summer. Recovery from the disease in the case of adolescents and adults is occasionally rapid and uncomplicated but unfortunately a number exhibit an intermittent type of feverthe temperature rising at intervals of a few days accompanied by a recurrence of headache and sometimes vomiting. It is often necessary during these attacks to withdraw fluid by Iumbar puncture. In the case of a large proportion of young children who recover a variable period characterised by hydrocephalic symptoms is passed through. During this stage special treatment in the form of nasal and rectal feeding is necessary owing to inability to swallow. The amount of emaciation is often extreme and the child may linger in this stage for weeks. Ultimately the appetite returns, the patient puts on flesh, and the mental condition becomes again active.

The largest quantity of fluid drawn off in any one case (recovery) was 171 drachms. Records were kept of the total amount of fluid drawn off by lumbar puncture. It measured 1342 drachms. Excluding four cases in which no puncture was performed this was an average of $16 \cdot 3$ drachms per case.

Sequela: (1) Deafness.-Of those which recovered four were absolutely deaf to both air and bone conduction on dismissal. In three other cases the deafness was temporary. In two of these hearing returned prior to discharge from hospital, and in the case of the third - a girl, aged 15 years-hearing to loud voice returned some months after leaving hospital.

(2) Paralysis. - In two of the recovered cases a spastic paresis of both lower extremities was met with. One of these was a female, aged 16 years, who suffered during convalescence from severe pain in the lumbo-sacral nerves. She made a good recovery, however, and was able to walk freely for some time prior to discharge. After being at home for a few weeks difficulty in walking again developed and she went into the Edinburgh Royal Infirmary for treatment. Unfortunately, she is now unable to walk without support. The second case was that of a child, aged four years, who was 240 days in hospital. At one stage she had marked hydrocephalic symptoms. She became blind, apparently deaf, mentally dull and aphasic, except for the monosyllable "Aye." Later, when volition again became active it was found that there was spastic paresis of both lower extremities with ankle clonus and exaggerated knee reflexes. Improvement was slow, but on discharge she was able to walk unaided, though still with a slightly spastic gait. In neither of these two cases was there involvement 
of the sensory nerves. None of the other patients who recorered showed symptoms of injury to the motor nerve tracts.

Motherwell.

\section{THIRTY-FIVE CONSECUTIVE CASES OF EXTRA-UTERINE PREGNANCY DEALT WITH BY ABDOMINAL SECTION WITHOUT A DEATH.}

By JAMES OLIVER, M.D. EDIN., F.R.S. EDIN., F.L.S., PHYSICIAN TO THE HOSPITAL FOR WOMEN, SOHO-SQUARE, LONDON.

EXTRA-UTERINE gestation is in these days a derangement of not infrequent occurrence, yet a clinical synopsis of 35 cases dealt with by abdominal section in the practice of one individual may be of interest and it may help to dissipate some of the erroneous impressions which exist regarding this remarkable phenomenon-impressions due to conclusions framed and promulgated on insufficient data. The group is a very varied one. It includes six cases in which the fotus had arrived at maturity and had died before delivery was effected and three in which the operation was performed after the development of the placenta was completed and whilst gestation was actively progressing. The majority of the cases, as is natural, were cases in which the embryo had perished at an early stage of its existence in consequence of a more or less extensive extravasation of blood caused by the rupture of one or more of the physiologically enlarging maternal ressels. One only is specified as an undoubted case of ovarian pregnancy, but I am constrained to believe that some of those in which the gestation sac was located in the broad ligament were also cases of ovarian pregnancy and my reason for expressing this belief is that had they ever been located in the tube internal hæmorrhage would have occurred and, moreover, we occasionally find true ovarian cysts in the mesometrium and there is no apparent reason why an actively progressing ovarian pregnancy should not also gradually insinuate itself into the substance of the broad ligament.

CASE 1. Full-time extra-uterine pregnanoy; gestation sao in left broad ligament; fotus dead.-The patient, aged 34 years, had been married for four years and had had one child. The child was born three years previously and was suckled for 14 months and was weaned because the menstrual discharge had reappeared. From this time until 12 months before the patient came under my care menstruation had recurred regularly. 12 months ago "a period" was missed and the patient considered herself pregnant. After seven weeks' amenorrhoea she had a severe attack of abdominal pain and fainted. On regaining consciousness she observed that there was a slight hamorrhagic discharge from the genitals. In two hours this discharge had ceased and she was quite herself again. After a lapse of four weeks there was again a slight hæmorrhagic discharge but no pain. After a period of six months, during which there was complete amenorrhœa, there was again "a slight show" of blood but still no pain. Three months later what the patient considered her usual menstrual discharge made its appearance. As, however, it had persisted for four weeks she consulted me. She had all along considered herself pregnant but she was not quite certain that she had ever felt movements. Colostrum was readily obtained from both breasts.

Operation.-A full-time female child with its placenta was abstracted from the left broad ligament. The peritoneal cavity was extensively opened. The sac was stitched to the anterior abdominal wall and drained.

CASE 2. Full-time extra-uterine pregnancy; gestation sac in right broad ligament; foetus dead.-The patient, aged 33 years, had been married for six years and had had two children; these were twins and they were born five years previously. Twelve months ago the patient missed two menstrual periods and when she considered herself ten weeks pregnant she was suddenly seized with severe abdominal pain, sickness, and diarrhœea. The sickness and diarrhœe soon subsided, but for nine and a half months she had complained more or less of abdominal pain. When five months pregnant "a fleshy piece" was passed without hæmorrhage, and this no doubt from its description was a large piece of so-called decidual membrane. A month later there was a "slight show" of blood from the genitals. The foetal movements were felt after about the fifth month but the patient could not remember when she ceased to feel them. After a period of practically 12 months' amenorrhoea delivery was effected by abdominal section. The breasts were flabby but colostrum was readily obtained.

Operation.-A full-time male child was removed from the right broad ligament. The placenta was not removed. The sac was stitched to the abdominal wall and drained. The abdominal incision opened the peritoneal cavity extensively.

CASE 3. Full-time extra-uterine pregnancy; gestation sao in left broad ligament; foetus dead.-The patient, aged 33 years, had been married for nine years and had had five children and one miscarriage. The last child was born three years previously and was suckled for 15 months. 15 months ago the menstrual discharge failed to make its appearance and for ten and a half months thereafter there was complete amenorrhoa. The menstrual discharge then reappeared and during the five months preceding her visit to me menstruation had recurred regularly and she was advised to see me because she had gone seven months over the time she expected to be confined and the abdomen was still large. The breasts were not characteristic of pregnancy and colostrum could not be obtained from them.

operation.-A full-time male child was extracted from a sac in the left broad ligament. This was effected without opening the peritoneum. The sac was drained. The placenta in pieces came away afterwards.

Since the operation this patient has been twice pregnant. On the first occasion she miscarried; on the second she carried the child to full time and was confined of a living child without trouble.

CASE 4. Full-time extra-uterune pregnanoy; gestation sac in a capsule connected with the right ovary, in a peritoneal sac resembling that of the tunica vaginalis.-The patient was aged 33 years and had been married for nine years. She had had three children and one miscarriage ; the last child was born three and a half years previously. 12 months ago the patient missed being unwell and for 11 months thereafter there was complete amenorrhoea. She had considered herself pregnant but nothing unusual happened until towards the end of the 11 months amenorrhoea when she observed that she had come unwell and as this hæmorrhage had persisted for 19 days she was advised to see me. She had never during the 11 months suffered any pain. She had felt the movements from about the fifth month. The breasts were characteristic in appearance and colostrum was obtained readily from both.

Operation.-The fotus with its placenta was removed from a sac connected with the right ovary. The greater portion of this sac was excised; the remainder was stitched to the abdominal wall and drained. The peritoneum in this case was opened very extensively.

CASE 5. Full-time ovarian pregnanoy; gestation sac containing foetus and placenta removed intact; foetus dead.-The patient, aged 39 years, had been married for 12 years and had had one child; the child was born 11 years previously. During the last 12 months there had practically been complete amenorrhoea. At the fourth, ninth, and tenth months of this amenorrhœal period there was a " mere show of blood." On the first of these occasions a fleshy piece, which no doubt was decidual membrane, was passed. About the time that the second period was missed the patient complained a good deal of abdominal pain and this troubled her altogether for three or four weeks. From this time onwards she experienced very little abdominal discomfort. The fotal movements had been felt but she was uncertain when she first felt them and when she ceased to feel them. The breasts were not characteristic in appearance but colostrum was obtained easily from both.

Operation.-The right mesovarium was ligatured and dealt with as in the case of any ordinary ovarian cyst and the tumour containing the fœetus and placenta was removed intact. The tumour was incised after it had been removed and the fotus and placenta were then for the first time brought into view.

CASE 6. Full-time extra-uterine pregnanoy; gestation sac in left broad ligament; foetus dead.-The patient, aged 37 years, had been married for 15 years and had had five children, the last child having been born ten years previously. 11 months ago a menstrual period was missed 